\title{
Gamblified digital product offerings: an experimental study of loot box menu designs
}

\author{
Martin Adam ${ }^{1}$ (D) $\cdot$ Konstantin Roethke ${ }^{1} \cdot$ Alexander Benlian $^{1}$ \\ Received: 7 April 2020 / Accepted: 30 March 2021 / Published online: 17 May 2021 \\ (C) The Author(s) 2021, corrected publication 2021
}

\begin{abstract}
To augment traditional monetization strategies, digital platform providers increasingly draw on gamblification (i.e., the use of gambling design elements). By means of gambling design elements (e.g., lottery tickets, scratch cards, loot boxes), platform providers do not only entertain users but also incentivize them to purchase digital products. Yet, despite the increasing prevalence of gamblified digital platforms, little is known about how gamblification influences user purchase behaviors. Drawing on prospect theory, we investigate gamblification in the form of loot box menu designs and the associated effects of uncertainty, loss experience and behavioral control on user purchase behavior. Specifically, we conducted a contest-based online experiment with 159 participants, finding that platform providers can profit from offering loot boxes with certain (vs. uncertain) rewards in loot box menus. Furthermore, this effect intensifies when participants previously experienced a loss and decreases when they perceive to have more control over the result. Thus, our findings provide theoretical and practical insights for a better understanding of gamblification in general and of loot box menu designs for enhancing digital business models in particular.
\end{abstract}

Keywords Gamblification · Gambling · Gamification · Digital business models · Loot box · Prospect theory

JEL Classification C91 · D91 · M38

\section{Introduction}

Because competition among digital platforms for regular and new customers has intensified, digital platform providers find it increasingly difficult not only to channel users to their platforms but also to encourage them to complete and repeat transactions (e.g., Roethke et al., 2020; Schneider et al., 2020; Weinmann et al., 2016). Consequently, digital platform providers attempt to enhance their digital business models and thus increasingly experiment with new monetization strategies based on digital design elements to complement and/or support their traditional revenue streams (e.g., sales, ads and subscriptions). One strategy to stand out in the fierce competition

Responsible Editor: Steven Bellman

Martin Adam

adam@ise.tu-darmstadt.de

1 Fachgebiet Wirtschaftsinformatik: Information Systems \& Electronic Services, Technische Universität Darmstadt, Hochschulstraße 1, 64289 Darmstadt, Germany is gamification, which can be defined as the use of game design elements (e.g., points, badges and leaderboards) to increase user engagement in the form of experiential (e.g., motivation, enjoyment) and instrumental outcomes (e.g., revenues, profit) (Liu et al., 2017). As such, gamification promises to enhance digital business models through fundamental changes in the way business is carried out and revenues are generated (Veit et al., 2014; Wagner et al., 2014).

A gamification-related but hitherto neglected phenomenon is gamblification, which we analogously define as the use of gambling design elements (e.g., lottery tickets, scratch cards, loot boxes) to increase user engagement. As such, gamblification and gamification usually share the same settings (e.g., a user interacts with a digital platform) and goals (e.g., user engagement) but work with different means to attain the goals: Whereas gamification adapts the digital platform through the levers of game design elements (e.g., Uber introducing badges, which have no to little value outside the Uber ecosystem) (Rosenblat \& Stark, 2016; Uber, 2020), gamblification uses the levers of gambling design elements (e.g., Starbucks utilizing an augmented reality lottery, providing users the prospect to win cash-equivalent rewards) (Starbucks, 2020). This difference 
introduces new opportunities to design digital platforms and thus digital business models. Gamblification broadly implies individual gambling design elements (e.g., dice, cards, chance-based mechanisms) that can be used in isolation or in combination. As such, gamblification impacts digital platforms' revenue streams (e.g., sales, ads and subscriptions) through improving user engagement with a digital platform (e.g., user onboarding, revisits, activity) (e.g., Shen et al., 2014; Fabbri et al., 2019; Mazar et al., 2017). For instance, Google Pay (Google, 2020) uses digital scratch cards and Starbucks (2020) employs augmented reality lotteries after the purchase of products to entertain users and incentivize repurchases, thus gamblifying their digital product offerings (see Fig. 1).

While gamification has been widely investigated enjoying immense popularity both among researchers and practitioners (e.g., Hamari \& Lehdonvirta, 2010; Hamari et al., 2014; Koivisto \& Hamari, 2019), there is only scarce knowledge on how gamblification is implemented and how it may influence purchase behaviors. More specifically, because users who face gamblified digital product offerings act in inherent uncertain environments, they are subject to psychological effects that may largely differ from non-gamblified interactions. As such, these effects may urge some users to be attracted by gamblified digital products offerings while others may refrain from any interaction with gamblified digital products offerings. In particular, loot boxes (i.e., virtual goods that contain chance-based selections of other virtual goods) are abundantly used gamblification design elements and have recently received increasing media and research attention (e.g., King \& Delfabbro, 2019; Macey \& Hamari, 2019; Griffiths, 2018).

Although some research indicates how to optimize the monetization of digital business models (e.g., Voigt \& Hinz, 2016; Guo et al., 2019), only recently the importance of focusing on user engagement and user decision-making in uncertain environments has been recognized (Harviainen et al., 2018). Moreover, it remains to be examined, particularly in the context of product offerings within digital business models that rely on loot boxes and related loot box menus, how platform providers can gamblify their menus to generate additional revenues and how users react to different loot box menu designs. Indeed, literature on consumer behavior documents that - depending on the context - gamblification design elements can trigger optimal or sub-optimal user behavior: One the one hand, an option with a reward of probabilistic uncertainty (i.e., random/chance-based/algorithm-based) can be more motivating and exciting than an option with a reward of a certain magnitude (Shen et al., 2014). On the other hand, substantial research has demonstrated that users are riskaverse and prefer certain rewards, even willing to pay a premium for this certainty (Von Neumann \& Morgenstern, 2007; Kahneman \& Tversky, 1979; Allais, 1953). As such, in the context of product offerings within digital business models that built on loot box menus to generate revenues, the question arises whether a certain (vs. uncertain) reward in a loot box menu can lead to improved user decision-making and thus higher revenues for the digital platform. Likewise, user behavior and decision making in gamblified environments are presumably governed to a larger extend by psychological effects that are less salient in non-gamblified environments. In particular, motivations such as ambition-to-win or fear-of-losing generally seem to be important behavioral drivers within gamblified environments. In this regard, it remains to be examined how these effects influence user behavior when faced with gamblified digital product offerings.

Against this backdrop, the objective of our study is to investigate (1) the effect of a certain (vs. uncertain) reward in
Fig. 1 Examples of gamblified digital product offerings




loot box menus - as a comparison of two different loot box menu designs - on user purchase behaviors (i.e., certainty effect); (2) how perceived loss experience - as a common experience in interactions with gambling design elements that may amplify the fear-of-losing-influence the certainty effect; and (3) how user perceptions in form of behavioral control - a perception that has been frequently analyzed in gambling literature and presumably reflects ambitions-to-win - influence the certainty effect. Consequently, we ask the following research questions:

RQ1: How do certain vs. uncertain rewards affect user purchase behavior?

RQ2: How do previous loss experience and perceived behavioral control interact with the effect of certain vs. uncertain rewards on user purchase behavior?

To investigate our research questions, we performed a contest-based online experiment with 159 participants. Drawing on prospect theory (Kahneman \& Tversky, 1979), we provide ideas on how gamblification can be employed and modified to increase revenue generation in digital business models through an enhanced loot box menu design. Our study contributes in three major ways to the still nascent research on gamblification in general and on loot box menu designs for enhancing digital product offerings within digital business models in particular: First, we contribute to previous IS research by shedding light on gamblification and providing insights into its role in the form of loot boxes, particularly the role of certain vs. uncertain rewards in loot box menu designs. Second, our study sheds light on two crucial moderators of the effect, namely previous loss experience and perceived behavioral control, which exhibit intriguing opposite moderating effect patterns on the effect of certain vs. uncertain rewards. Third and last, addressing the call for future research into the cognitive dimension of digital decision contexts (Goes, 2013), we add to the emerging literature on cognitive biases in virtual environments by deriving actionable and easily implementable design recommendations for loot box menus designs.

\section{Theoretical background}

Gamification has become an established phenomenon in IS research (e.g., Liu et al., 2017; Hamari et al., 2014; Schöbel et al., 2020; Huotari \& Hamari, 2017). For instance, through the earning and collection of digital points, users can demonstrate their performance in leaderboards and thus drive competition and excitement among users of the digital platform (Liu et al., 2019). Excitement surrounding gamification results from its many potential organizational and commercial benefits, such as making monotonous tasks enjoyable (Thiebes et al., 2014) and allowing for cost savings and performance improvements (Penenberg, 2015). Consequently, organizations and digital platforms apply gamification in various ways to engage, steer and nudge all kinds of individuals toward desired goals (e.g., Roethke et al., 2020; Weinmann et al., 2016; Adam et al., 2020; Schneider et al., 2020).

Although IS researchers have paid considerable attention to gamification, little research has been conducted on gamblification. We consider gamblification a gamificationrelated but under-investigated phenomenon and analogously define the term as the use of gambling design elements. The term covers both the employment of isolated or combined gambling design elements without necessarily incorporating full-fledged gambling in the context. In addition to a general elaboration of this business practice (i.e., gamblification in various business settings), the particularities in an online setting - especially through the augmented possibilities of interactivity and multi-media content - are especially interesting and worthwhile for gamblification as an information systems phenomenon.

Loot boxes are gamblification design elements in the form of virtual goods that have substantially increased in importance and can be usually bought by users to gain a selection of goods (Hamari \& Keronen, 2017; Macey \& Hamari, 2019). Loot boxes typically contain one or more contents from a set of different virtual goods, which are not necessarily obtained with certainty, but with a specific probability (e.g., a loot box can contain several goods, one with a $50 \%$ chance, another with a $25 \%$ chance, etc.) (Overwatch Wiki, 2019). To generate additional revenue and to provide a rich user experience, an loot box menu of different prized loot boxes is usually offered, where the more expensive loot box contains the "better deal" (e.g., the same good can be obtained with a $40 \%$ increased chance of winning, but only a $15 \%$ price increase) (Riot Games, 2019). Loot boxes and related loot box menu designs are particularly interesting for two main reasons: First, from a theoretical perspective, these gamblification design elements inspire intriguing new research questions and may ultimately provide novel theoretical insights. Second, from a practical perspective, loot boxes are the most common and successful forms of gamblified digital product offerings within digital business models. Indeed, loot boxes do not only represent predominant means of monetization in most freeto-play gaming (e.g., Fortnite, Battle Royale and League of Legends) (e.g., Koch \& Benlian, 2017; Wagner et al., 2014), but have also increasingly become prevalent in fully priced games and many other gamblified digital business models (e.g., Forza 7 and Overwatch) (Macey \& Hamari, 2019). Thus, the analysis of loot boxes and related loot box menu designs is of utmost importance for platform providers who rely on the success of these gamblified design elements to increase revenues and even ascertain the prosperity and sustainability of their business. 
Despite the prevalence of gamblification in practice, the question still remains how to gamblify digital product offerings to optimally leverage uncertain outcomes in the design of loot box menus to increase user engagement (e.g., Liu et al., 2017; Hamari \& Lehdonvirta, 2010). Indeed, researchers recommend that users need to appreciate the possible lotteryresults without the feeling that the gambling experience is deliberately designed to extract revenues (Hamari \& Keronen, 2016), thus promoting purchases without impeding user experiences (Hamari \& Keronen, 2017). For instance, Starbuck's Starland (2020) multi-million dollar event transformed the rather profane purchase of coffee into an exciting gambling adventure through an in-app augmented reality lottery for 16 million Starbucks Rewards members, only to entertain and incentivize further Starbuck's visits and purchases. However, despite acknowledging the importance of how goods should function and how to visually design them within the specific digital surrounding, there has been only scant research on the effects of designing reward option menus (e.g., loot box menus), such as the conditions under which goods can be purchased (Hamari \& Keronen, 2016; Harviainen et al., 2018).

Previous research has revealed that uncertainty can enhance motivation in form of investments in effort, time and money (Shen et al., 2014). Likewise, uncertain incentives in the form of uncertain price promotion has been demonstrated to evoke the same level of positive responses compared to certain incentives (Goldsmith \& Amir, 2010). Moreover, in the context of retailing Mazar et al. (2017) highlights that consumers prefer a probabilistic free price promotion to the deterministic price promotion. However, when promotions displayed very high probabilities (greater than 90\%) no evidence for the aforementioned preference of probabilistic to deterministic price promotions was found. Besides research on consumer behavior, the effect that the result of people's evaluation when comparing two lotteries changes if one of the lotteries is riskless has been as well investigated in the context of gambling (Bleichrodt \& Schmidt, 2002; Wärneryd, 1996).

Moreover, previous research has indicated that crucial contextual variables, such as previous loss experience (Tversky \& Kahneman, 1973) and perceived behavioral control (Weinstein \& Lachendro, 1982), can define and severely influence the experience of uncertain offerings and thus the decision outcome. Because uncertainty is a defining aspect of gamblified interactions, these interactions are arguably affected by psychological mechanisms relevant for decision making under uncertainty (e.g., ambition-to-win or fear-of-losing) to a larger extent compared to interactions that involve little or no uncertainty. Since interactions within such uncertain environments are central to and characteristic for gambling, insights from research on gambling behavior are instructive to investigate interactions with product offerings in gamblified digital business models. In the context of gambling behavior, a substantial amount of research has demonstrated that previous loss experience may evoke fearsof-losing. As such, these previous loss experience frequently alters gamblers' risk-perception and thus influences subsequent gambling behavior (Croson \& Sundali, 2005; Guryan \& Kearney, 2008). For instance, Croson and Sundali (2005) showed that $80 \%$ of subjects quit roulette gambling after losing on a spin, but only $20 \%$ did so after a winning spin. Likewise, perceived behavioral control and the related optimism bias (Klein \& HelwegLarsen, 2002) may boost ambitions-to-win and have been investigated as important drivers of engaging in gambling behavior in particular (Gibson \& Sanbonmatsu, 2004; Rogers, 1998). Consequently, the certainty effect, previous loss experience and perceived behavioral control are crucial aspects that have demonstrated to individually influence gambling behavior and are important to consider when investigating gamblification design elements involving uncertainty (i.e., the purchase of loot boxes) to provide a better and more holistic understanding of the role and effectiveness of uncertain vs. certain reward in loot box menus. Taken together, insights from consumer behavior and gambling literature demonstrate that uncertainty regarding the conditions under which loot boxes are sold can enhance motivation and increase purchases. Since probabilistic outcomes are defining features of gamblification design elements (in contrast to gamification design elements) and thus of loot box menus, it stands to reason to investigate the underresearched question of how probabilistic uncertainty regarding the result of the purchase of loot boxes affects user purchase decisions and how previous loss experience and perceived behavioral control moderate this effect.

\section{Research model and hypothesis development}

Drawing on prospect theory (Kahneman \& Tversky, 1979), we develop a research model that illuminates the effects of altering the eligible probabilities of receiving a reward on users' choices between two loot boxes (H1). We hereby compare whether user purchase behavior changes when users are confronted with two loot boxes with uncertain outcomes (i.e., uncertain \& uncertain) vs. one loot box with an uncertain outcome and one loot box with a certain outcome (i.e., uncertain \& certain), while keeping the expected values similar for each decision. We then continue by elaborating on the interaction effect between altering probabilities of receiving rewards and a previously experience of loss (H2) as well as on the interaction effect between altering probabilities of receiving rewards and perceived behavioral control (H3). In the 
Fig. 2 Research model

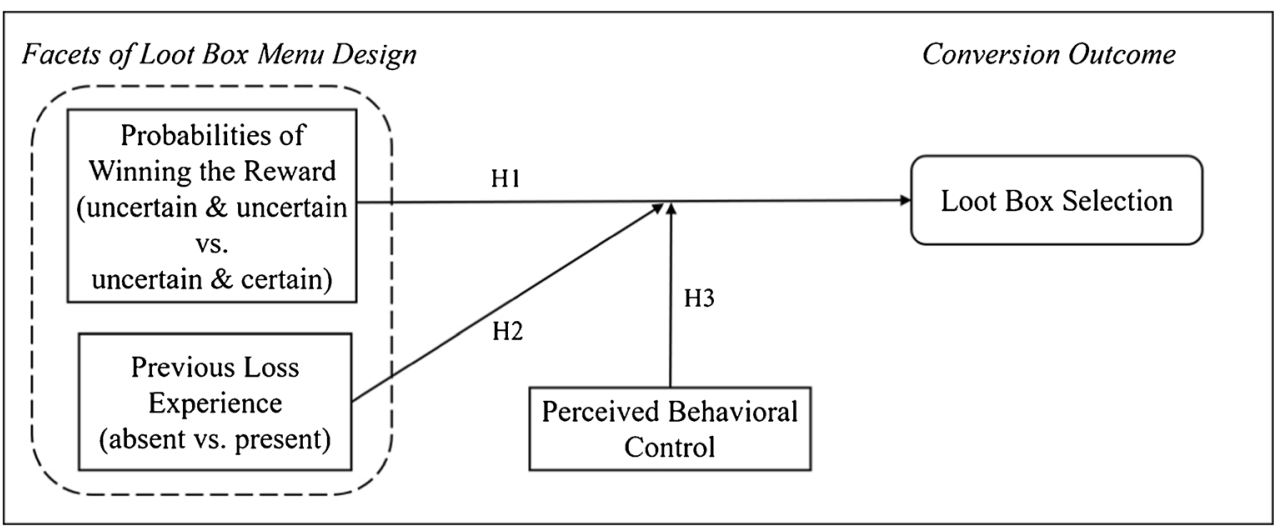

following sections, we expound upon each of the posited relationships depicted in Fig. 2.

\section{Main effect of reward winning probability on loot box selection}

According to prospect theory (Kahneman \& Tversky, 1979), people overweight small probabilities and underweight high (near certain) probabilities, being contrary to implications from expected utility theory. This propensity can lead to inconsistencies where the same individual acts risk-averse and risk-seeking, depending on whether the occurrence probability of a risk-involving event is high or low (Allais, 1953; Von Neumann \& Morgenstern, 2007). The underweighting of high (near certain) probabilities leads to a risk aversion phenomenon manifesting in a systematic preference of a certain gain over a near certain chance of winning a reward.

In contrast to expected utility theory, which predicts a preference of the loot box with a higher expected value, this risk averse preference even develops when the expected value is higher for the uncertain outcome than for the certain gain. When the outcome of both loot boxes is uncertain, this systematic risk-averse preference does not occur and a riskseeking behavior in line with predictions from expected utility theory (i.e., selection of the riskier loot box if it yields a higher expected value) can be observed. An explanation for this change in risk preferences is provided by the certainty effect. It refers to a psychological effect resulting from a reduction in the probability of winning a reward from certainty to uncertain (e.g., from $100 \%$ to $75 \%$ ) which induces a perception of greater loss than a corresponding reduction (e.g., from $80 \%$ to $60 \%$ ) in the probability from uncertain to more uncertain (Tversky \& Kahneman, 1986).

Thus, we argue that when users face a decision to choose between two differently priced loot boxes with the same expected value, they are more likely to choose the more expensive loot box if it is certain vs. if it is uncertain. This is in accordance with previous research on the certainty effect (e.g., Tversky \& Kahneman, 1986; Daniels \& Zlatev, 2019; Mazar et al., 2017) in that users prefer certain gains over uncertain gains.

$\mathrm{H} 1$ When faced with a choice to purchase one of two differently-priced loot boxes with the same expected value, users are more likely to choose the more expensive loot box if it features a certain gain vs. when it features only an uncertain gain (i.e., certainty effect).

\section{Interaction effect of reward winning probability and previous loss experience}

Next, we look at the interaction effect of certainty effect and perceived loss experience - a common experience in interactions with gambling elements. To hypothesize on the interaction effect we draw on the availability heuristic, which refers to the biased evaluation of probabilities which is skewed towards information more readily available (Tversky \& Kahneman, 1973). According to this heuristic, people evaluate the probability of uncertain events depending on previous experience and examples related to that event that immediately come to a given person's mind. If a related previous experience or example can be vividly recalled, the probability of the event in question will be evaluated higher compared to situations where a related examples or experiences cannot be recalled. Consequentially, because recent information can be retrieved more easily, people tend to weight their judgment toward more recent information.

Accordingly, we propose that when users experience a loss (i.e., a gambling element does not contain the desired good), users' motivation to engage in further gambling (i.e., subsequent purchase of loot boxes with uncertain content) will be impeded. This is also in line with substantial research on gambling, demonstrating that the availability heuristic can explain why recent loss experiences is negatively correlated with subsequent risk seeking in that previous loss experiences drives users to overestimate their chances to lose (e.g., Ma et al., 2014; Goodie \& 
Fortune, 2013; Fortune \& Goodie, 2012). Consequently, we hypothesize that when users choose between the certain and the uncertain loot box, previous loss experience will boost the certainty effect such that users prefer the certain gain.

H2 Previous loss experience (vs. no such experience) amplifies the certainty effect.

\section{Interaction effect of reward winning probability and perceived behavioral control}

An important precondition for users to participate in and enjoying gambling is their believed skill to master the challenges and objectives they encounter while gambling. If they perceive that they have the necessary knowledge and capabilities (i.e., perceived behavioral control) to master gambling, they enjoy gambling and focus their attention on the affective experience of gambling rather than on the outcome of gambling (Takatalo et al., 2010; Shen et al., 2014). In this regard, optimism bias, defined as the irrational assessment of one's own behavioral control in a given situation and the belief to be less likely to experience negative events (Dunning et al., 2004; Klein \& Helweg-Larsen, 2002), seems to be a strong predictor for increased risk-taking (i.e., choosing an uncertain loot box).

In light of this, we investigate user perceptions in form of behavioral control - a perception that has been frequently analyzed in gambling literature. We suggest that when users choose between the certain and the uncertain loot box, perceived behavioral control attenuates the certainty effect such that users prefer the uncertain reward. Indeed, extant research has investigated that biases from personal assessment about one's own capabilities can lead to an overly optimistic evaluation of situations and to increased risk-taking increasing ambitions-to-win (Weinstein \& Lachendro, 1982; Dunning et al., 2004). Specifically previous research on digital business models demonstrates that conversion behavior is influenced by biased risk assessments, such that situations are overly optimistically evaluated which leads to increased risk-taking (Koch \& Benlian, 2017; Helweg-Larsen \& Shepperd, 2001). Given the above arguments and empirical evidence, we hypothesize that.

H3 Perceived behavioral control attenuates the certainty effect.

\section{Research methodology}

In the following, we describe how our experiment was designed and implemented as well as how we operationalized the probabilities of winning the rewards and previous loss experience. Further, we discuss the choice, the reliability and validity of the variables we chose to measure.

\section{Experimental design and treatments}

In line with procedures in previous online experiments (e.g., Lowry et al., 2013; Koch \& Benlian, 2017), the study was framed as a warm-up for a subsequent online contest in a self-developed game, where users had the chance of winning $€ 20$ depending on their performance. Consequently, our entire experiment was aligned to ascertain that (1) it replicates a real surrounding in which gamblification elements could potentially exist and (2) users were well motivated and involved in the upcoming decisions of the experiment. To comprehend the overall setting and which steps participants completed in the course of the study please refer to Fig. 5. However, to fully understand the procedure, first we explain how the overall setting built upon the game and the connected procedure.

Prior to participating in the contest, the tutorial explained the controls and mechanics of the game which was inspired by the classic game "Snake." As depicted in Fig. 3, the game featured a representation of the eponymous reptile which was navigated by the player. The goal was to prevent the snake from colliding with the walls and its tail as well as to guide it to pieces of food which are represented by red pixels randomly generated on the screen. After the snake was successfully navigated to a piece of food, which was subsequently eaten, the length of the snake and the players' score increased. If the player's navigation led to a collision, the game restarted. After the tutorial, participants could test the game and train their skills for $2 \mathrm{~min}$ in preparation for the contest which took the same amount of time. In a subsequent step, a loot box offering the chance to gain extra playtime in exchange for a part of the potential contest reward was presented. We introduced the conditions of the contest to participants as follows: "After the survey is finished, you will be able to play the game again in a competition. The $50 \%$ best competitors have the chance to win one of three Amazon vouchers".

The score achieved during playing the game determined which participant would be among the $50 \%$ best participants. The score increased with every successful navigation of the snake to a piece of food. Starting with 10 points for the first piece of food, every time the snake successfully navigated to an additional piece of food the score obtained for eating another piece of food increased (11 points for the 2 nd piece, 12 points for the 3 rd piece, etc.). After a collision of the snake with the wall or its tail, the game continued but the points for eating a piece of food reset to 10 points and increased again in the manner descripted above. The score, however, was saved such that every further successful navigation adds to the score already obtained. Therefore, extra playtime indirectly led to a higher score and thus increased the chance for a participant to be among the best $50 \%$ participants that were eligible for winning a voucher.

We chose to present a loot box including a reward with functional attributes because this category of goods can be 
Fig. 3 Experimental version of "Snake"

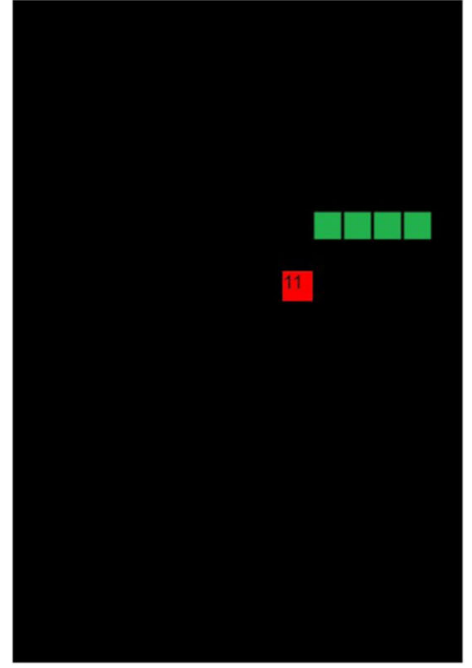

Zeit: 01:00 Minuten Score: 20

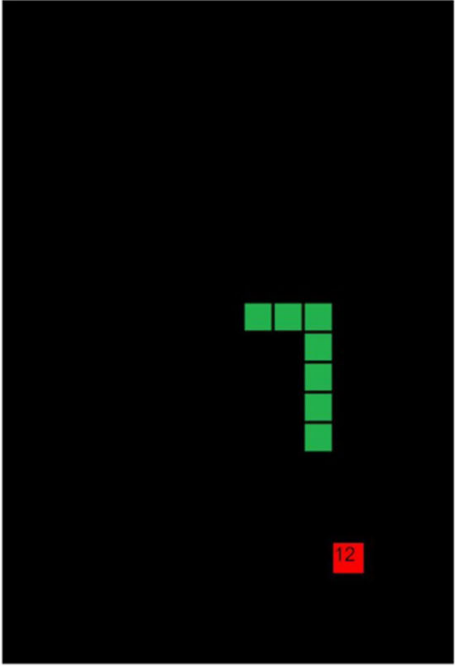

Zeit: 00:12 Minuten Score: 82 unambiguously operationalized and manipulated without lying out a complex story and environment (Lehdonvirta, 2009; Hinz et al., 2015). Participants had to choose between two loot boxes in exchange for either $€ 4$ or $€ 6$ where the cheaper loot box provided a ten percentage points smaller chance of gaining extra playtime compared to the more expensive loot

Fig. 4 Manipulation treatments

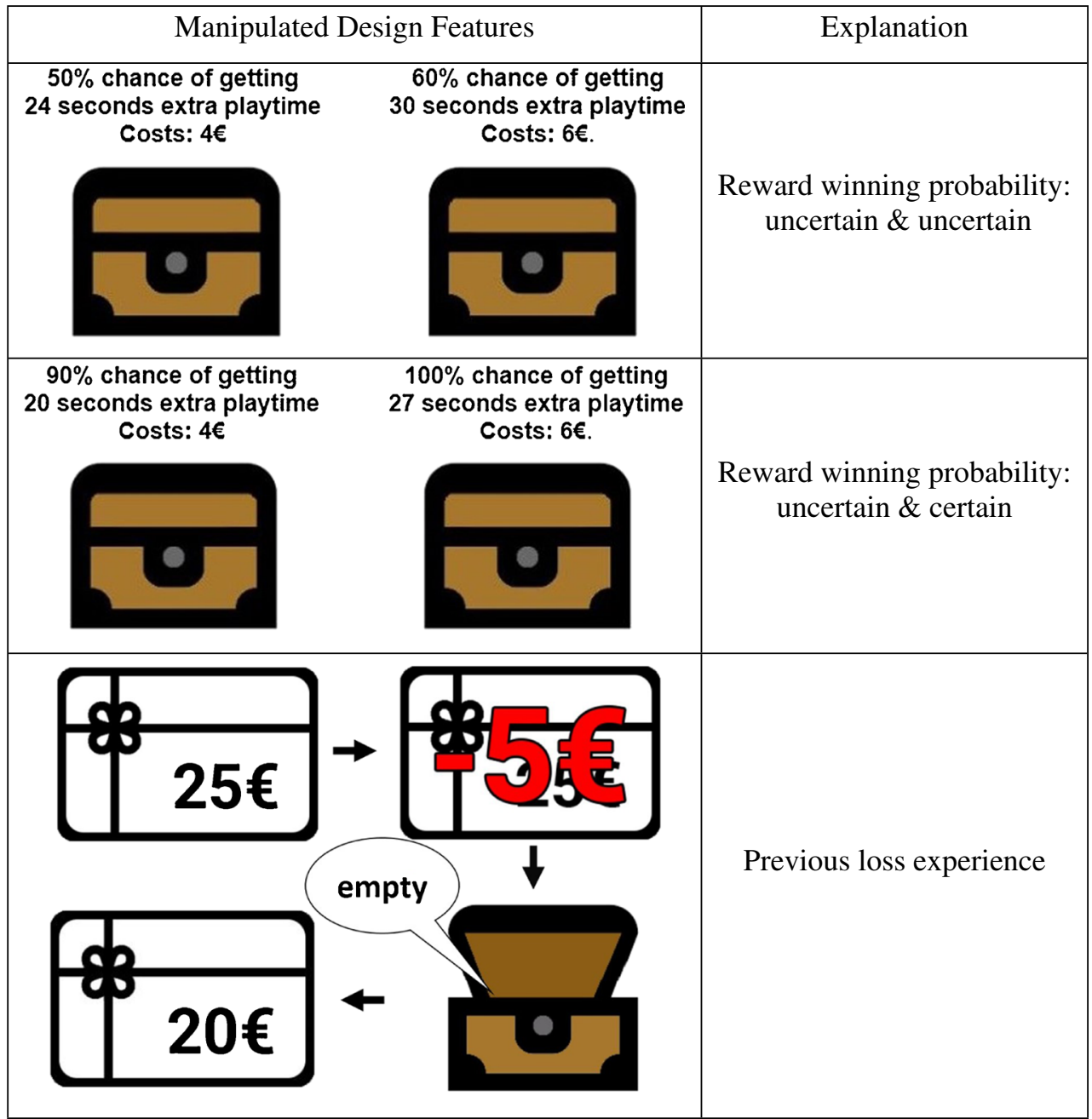


box (see Fig. 4). However, the expected value of the price for both loot boxes was identical. In our online experiment two independent variables (probabilities of winning the reward (PWR) and previous loss experience (PLE) were manipulated with a 2 (probabilities of winning the reward: uncertain and uncertain vs. uncertain and certain) $\times 2$ (previous loss experience: absent vs. present) between subjects, full-factorial design (e.g., Benlian, 2015).

\section{Manipulations and measured variables}

To implement our probabilities manipulations, we displayed different versions during the loot box selection event. As depicted in the upper part of Fig. 4, in the condition probabilities of winning the reward: uncertain and uncertain participants could choose between a $50 \%$ chance of getting $24 \mathrm{~s}$ extra playtime for $€ 4$ or a $60 \%$ chance of getting 30 s extra playtime for $€ 6$ (resulting in the same expected value of $3 \mathrm{~s}$ per $€$ ).

Whereas in the condition probabilities of winning the reward: uncertain and certain (middle part of Fig. 4) the choice was changed to a $90 \%$ chance of getting $20 \mathrm{~s}$ extra playtime for $€ 4$ vs. a $100 \%$ chance of getting $27 \mathrm{~s}$ extra playtime for $€ 6$. To rule out expected utility-driven behavior, we designed all manipulations in such a way that the expected value of the price for both eligible loot boxes was identical (e.g., $3 \mathrm{~s}$ per $€$ in the condition uncertain and uncertain) and thus equally attractive in regard of their expected value. We choose $50 \%$ $\& 60 \%$ and $90 \% \& 100 \%$ as probabilities because these are among the proposed combinations that were used when researchers first investigated and introduced the certainty effect (Allais, 1953; Kahneman, 2011). The proposed prices (i.e., $€ 4$ $\& € 6)$ were used because they are within the range of prices for contemporary loot boxes (e.g., Riot Games, 2019; FIFA Analytics, 2020; FIFAUTEAM, 2020).

Prior to loot box selection, to create a previous immediate loss experience, participants in the condition previous loss experience: present had to purchase a separate loot box that could contain up to $€ 10$ in exchange for a $€ 5$ reduction of their winnable amount. Participants were told prior to the loss event that their total winnable amount is $€ 25$ (instead of $€ 20$ like the other group). As the lower part of Fig. 4 exhibits, the $€ 5$ reduction is illustrated through visualizations of the remaining winnable amount and by a depiction of the empty loot box representing the loss event.

To start the process subjects clicked on a web link. As depicted in Fig. 5, we segmented the experiment into five parts. The first part introduced the experiment's outline and the conditions of the contest (Step 1). Second, the game practices were explained and the tutorial (i.e., warm-up) with the training session started (Step 2). Third, participants in the condition previous loss experience present received a virtual chest in exchange for $€ 5$ of their potential reward with the information that the chest contains up to $€ 10$ of extra winnable reward but that it can also contain nothing what was actually the case. Afterwards participants in the previous loss experience condition were informed that their winnable amount in form of a voucher decreased from $€ 25$ to $€ 20$. In this step participants in the condition previous loss experience absent were informed that their winnable amount in form of a voucher was $€ 20$ (Step 3). The fourth step introduced the loot box selection event featuring two treasure chests with specific probabilities attached to contain extra play time for the contest providing the opportunity to earn extra points. Participants had to choose between two loot boxes. One loot box could be bought in exchange for a $€ 4$ reduction of the winnable reward and the other for a $€ 6$ reduction. Both loot boxes were labelled with a numeric combination of probability and extra playtime (e.g., 50\% and $24 \mathrm{~s}$, see the upper two panels of Fig. 4) (Step 4). In the last step participants were guided to a post-experiment questionnaire which assessed demographics, previous gaming experiences and other variables (Step 5). Afterwards, the contest was conducted. However, because all participants could choose to participate in the contest or not, only the warm-up but not the actual contest was part of the experiment. Because all participants invested similar time and effort we wanted to make sure that no treatment

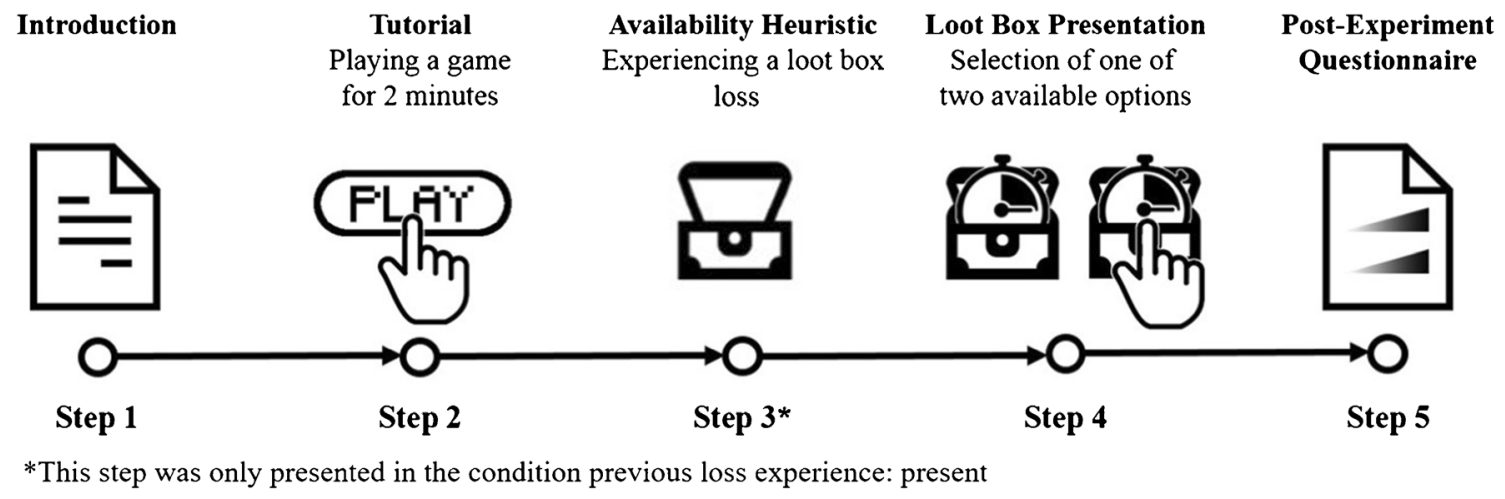

Fig. 5 Experimental procedure 
favored a specific group. Therefore, for ethical reasons, all participants had the choice to play for $2 \mathrm{~min}$, regardless which condition was assigned to them. Afterwards, all participants who chose to provide their email address could potentially win one of three $€ 20$ Amazon vouchers.

The connection of the experiment and the contest was necessary so that participants had something at stake (i.e., "skin in the game"), motivating them to carefully consider their decision. Further, this combination was chosen to make the user understand during the warm-up why the content of the loot box is useful in the context of the game and thus for the contest.

We measured participants' purchase decision (selection of the more expensive loot boxes), and whether they experienced a loss event previously. Both decisions were captured. Participants were then directed to the post-experimental questionnaire, where we recorded our moderating construct (i.e., perceived behavioral control) and our control variables to rule out alternative explanations. Perceived behavioral control was measured on a 7-point Likert scale ranging from (1) strongly disagree to (7) strongly agree using two items based on (Hong \& Tam, 2006) (see Table 3 in Appendix A).

We measured the following alternative drivers for loot box selection in our experiment drawing on previous IS adoption literature (Gray \& Durcikova, 2005; Hong \& Tam, 2006; Fuller et al., 2009), namely risk aversion, perceived monetary value, and product involvement. For all items, a 7-point Likert-type scale was employed with values ranging from strongly disagree (1) to strongly agree (7). We chose the construct risk aversion because the decision involved risk (i.e., potential loss of money) and could be thus governed by general attitudes toward risk. Perceived monetary value was included because we wanted to rule out that the certain loot box had only be chosen due to its higher perceived value, not because it was certain. Likewise, we measured product involvement and loot box spending to rule out that the decision to choose the more expensive loot box was driven by a general interest in loot boxes/previous spending on loot boxes.

For our constructs, the reliability was measured by using Cronbach alpha, composite reliability (CR) and average variance extracted (AVE) (see Table 3 in Appendix A). The alphas of the constructs had a value above .75 , which is a proper value. The $\mathrm{CR}$ of all constructs was above .5 , which is also a satisfying value. The AVE met the requirements for a suitable level of reliability as well (Fornell \& Larcker, 1981). Furthermore, we collected information on subjects' gaming experience, previous spending on loot boxes (see Table 4 in Appendix A), and demographic information. We further employed checks to assure the comprehension of all instructions and included two manipulation check questions to ascertain that our manipulations were perceived and remembered correctly.

\section{Sample description and manipulation checks}

Similar to previous experiments in contest-based studies (e.g., Koch \& Benlian, 2017; Lowry et al., 2013; Ho et al., 2011), we recruited participants via social media from a subject pool of students operated by a large German university. The pool of participants were recruited from various media channels (e.g., flyers, and online advertisement) to assure a heterogeneous sample and limit any potential selection biases (MacKenzie et al., 2011). We choose to draw our sample from a student subject pool because they are highly knowledgeable regarding digital games and are typically also among the most frequent buyers of loot boxes (Juniper Research, 2017).

We conducted a power analysis using $\mathrm{G}^{*}$ power 3.1 (Faul et al., 2009; Schneider et al., 2020) specifying the parameters as follows: four groups ( $2 \times 2$ full-factorial design), a moderate effect size, and a desired power level of .90 . The results yielded that a sample size of 143 is sufficiently powerful to detect significant effects (Baroudi \& Orlikowski, 1989; Cohen, 1992). Out of a total of 217 participants, we excluded 24 due to suspicious click patterns (e.g., low response variability, high rate of missing values) and 34 due to failing at least on attention or manipulation check (Benlian et al., 2020), resulting in a final sample of 159 participants used for data analysis. Of the 159 subjects, 71 were females and 88 were males. 97 participants purchased the more expensive loot box, which results in an overall proportion of $61 \%$ across all four subgroups. Table 1 summarizes the descriptive statistics of the data.

Table 1 Descriptive statistics of demographics, controls and dependent variables

\begin{tabular}{lcc}
\hline & Mean & StD \\
\hline Demographics & & \\
Age & 25.5 & 8.43 \\
Gender (male) & $55 \%$ & \\
Moderator & & \\
Perceived behavioral control & 6.12 & 1.01 \\
Controls & & \\
Perceived monetary value & 5.02 & 1.41 \\
Risk aversion & 4.09 & .99 \\
Gaming experience & 11.37 & 8.93 \\
Product involvement & 2.60 & 2.05 \\
Loot box spending & 1.22 & .55 \\
\hline
\end{tabular}

Note: All variables with exception of Gender (binary) and Gaming Experience (years) were measured on 7-point-Likert Scales 
Table 2 Logistical regression analysis on loot box selection

\begin{tabular}{|c|c|c|c|c|}
\hline & \multicolumn{2}{|l|}{ Stage 1} & \multicolumn{2}{|c|}{ Stage 2} \\
\hline & Coef. & SE. & Coef. & SE. \\
\hline Intercept & $-4.71 *$ & 1.02 & -6.46 & 2.27 \\
\hline \multicolumn{5}{|l|}{ Manipulations } \\
\hline PWR & $.92 *$ & .37 & $4.60 *$ & 2.62 \\
\hline PLE & .45 & .38 & -.25 & .52 \\
\hline $\mathrm{PBC}$ & .06 & .18 & .70 & .27 \\
\hline \multicolumn{5}{|l|}{ Interaction } \\
\hline PWR x PLE & - & - & $1.77 *$ & .80 \\
\hline PWR x PBC & - & - & $-.73 *$ & .41 \\
\hline \multicolumn{5}{|l|}{ Controls } \\
\hline Perceived monetary value & .09 & .14 & .11 & .14 \\
\hline Risk aversion & .13 & .23 & .13 & .23 \\
\hline Gaming experience & .02 & .02 & .01 & .02 \\
\hline Product involvement & .17 & .11 & .22 & .12 \\
\hline Loot box spending & .39 & .48 & .29 & .50 \\
\hline Gender (male) & -.04 & .27 & -.05 & .39 \\
\hline Age & .00 & .02 & .00 & .03 \\
\hline \multicolumn{5}{|l|}{ Model fit } \\
\hline Log likelihood & -87.56 & & & -91.80 \\
\hline Nagelkerke $\mathrm{R}^{2}$ & .22 & & & .28 \\
\hline
\end{tabular}

Note: $\mathrm{p}<.05 ; \mathrm{p}<.01 ; p<.001 ; N=159 ;$ Coef. Coefficient, SE Standard error, $P W R$ Probabilities of winning the reward, $P L E$ Previous loss experience, $P B C$ Perceived behavioral control

\section{Results}

\section{Main effect of changing the probabilities of winning}

As Table 2 exhibits, to test our hypotheses, we conducted a two-stage hierarchical logistic regression on our dependent variable loot box selection. In the first stage, we entered all control variables, as well as our independent variables probabilities of winning the reward (PWR), previous loss experience (PLE), and perceived behavioral control (PBC). In the second stage, we added the interaction term of PWR and PLE as well as the interaction term of PWR and PBC. Nagelkerke's $\mathrm{R}^{2}$ was computed to test the fit for both stages.

None of our controls had a significant effect on selection decisions. The results of our logistic regression's first stage demonstrated a significant positive main effect of changing probabilities of winning the reward $(\mathrm{b}=.92$; Wald statistic $(1)=6.50 ; p<.05)$ on loot box selection, supporting H1. Hence, participants that were faced with a choice potentially governed by the certainty effect were more likely to select the more expensive loot box compared to when both probabilities of winning the reward were uncertain. The average revenue per decision in the group with only uncertain loot boxes was
$€ 4.98$ and in our scenario with one certain loot box $€ 5$.46. Thus, the change in preference due to employing the certainty effects results in an average increase in revenue of $€ 0.48$ per purchase $(+9.6 \%)$.

\section{Interaction effect analysis of changing the probabilities of winning and previous loss experience}

Moreover, our second stage unveiled a significant two-way interaction of changing probabilities of winning the reward and previous loss experience $(b=1.67$; Wald statistic $(1)=$ $4.52 ; p<.05)$ on the propensity to select the more expensive loot box, supporting H2. The positive interaction term suggests that the effect of changing probabilities of winning the reward on loot box selection is amplified when a previous loss event is experienced. With regard to monetary consequences, this positive interaction is associated with an average increase in revenue of $€ 0.82$ per purchase $(+16.2 \%)$.

To further evaluate our $\mathrm{H} 2$ hypothesis, we conducted a contrast analysis. As depicted in Fig. 6, the results highlight that when probabilities of winning were uncertain and certain, participants are more likely to select the more expensive loot box when previous loss experience is present compared to when it is absent $(86 \%$ vs. $62 \% ; \mathrm{F}=6.418 ; p<.05)$. However, a significant difference in loot box selection between the presence $(45 \%)$ and absence $(54 \% ; \mathrm{F}=.614 ; p>.1)$ of previous loss experience did not emerge when probabilities of winning were uncertain and uncertain, in support of $\mathrm{H} 2$.

\section{Interaction effect analysis of changing the probabilities of winning and perceived behavioral control}

The results of the second stage additionally indicated a significant two-way interaction between changing probabilities of winning the reward and perceived behavioral control $(b=$ -.77 ; Wald statistic $(1)=3.86 ; p<.05)$ on the propensity to select the more expensive loot box, supporting H3. The negative interaction term documents that the effect of changing probabilities of winning the reward on loot box selection is attenuated by perceived behavioral control. As such, the change in preference due to the certainty effect when perceived behavioral control is high results in an average increase in revenue of only $€ 0.30$ per purchase $(+6.0 \%)$.

Likewise, to investigate our $\mathrm{H} 3$ hypothesis, we conducted a contrast analysis as exhibited in Fig. 7. The results illuminate that when perceived behavioral control was low (i.e., when PBC exhibited a value of smaller than 6), participants are more likely to select the more expensive loot box when probabilities of winning were uncertain and uncertain opposed to when they were uncertain and certain $(39 \%$ vs. $86 \% ; \mathrm{F}=12.43 ; p<.01)$. However, in support of $\mathrm{H} 3$, when perceived behavioral control was high (i.e., when PBC exhibited a value equal to or higher 
than 6), no significant difference in terms of selection of the more expensive loot box occurred when probabilities of winning were uncertain and uncertain as opposed to when they were uncertain and certain $(53 \%$ vs. $69 \% ; \mathrm{F}=2.80 ; p>.05)$.

\section{Discussion}

Digital platform providers find it increasingly difficult to compete for regular and new customers and therefore experiment with various new monetization strategies to increase revenues and thus enhance digital product offerings within their digital business models. One emerging and promising strategy is gamblification, which complements and supports traditional revenue streams through a gamblified design of digital product offerings. Against this background, our research was guided by two research questions. The first research question focused on the effect of certain vs. uncertain rewards in loot box menus on user purchase behavior. The findings support our premise that the probabilities of winning rewards in loot box menus influence users' loot box selection.

Our second research question sheds light on the moderating role of previous loss experience and perceived behavioral control, two factors that had a potentially intriguing effect on the certainty effect. Our results reveal that previous loss experience augments the effect of different probabilities of winning on users' loot box selection. Although the effects of this changed evaluation of the uncertain loot box should be unambiguous when users have a choice between a certain and an uncertain loot box (i.e., they should be more likely to opt for the certain loot box), it is less straight forward for the situation involving the choice between two uncertain loot boxes. On the one hand, participants could be urged to opt for the less risky loot box with less monetary resources at stake (i.e., the

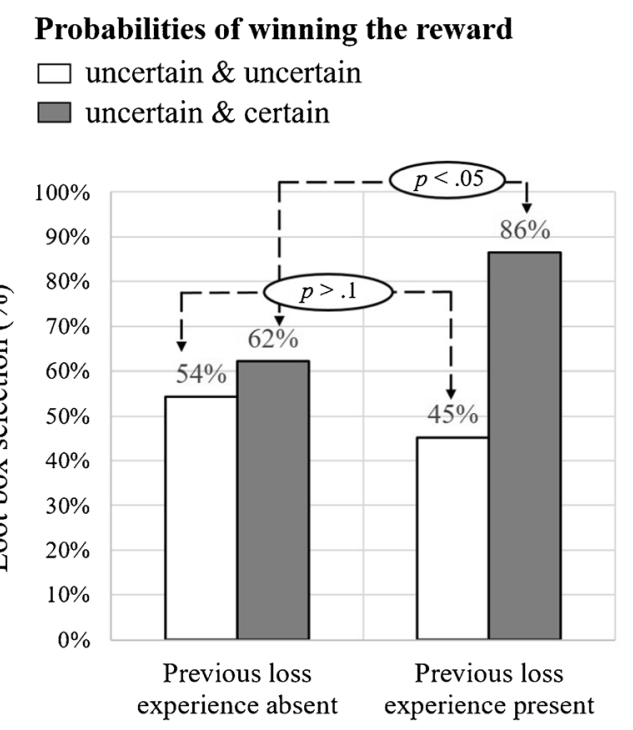

Fig. 6 Loot box selection when PLE is absent vs. present cheaper loot box). On the other hand, to counterbalance the previously experienced loss (i.e., "break-even effect") (Thaler \& Johnson, 1990), participants could be as well urged to opt for the loot box with the potentially higher reward, despite the higher stakes involved. Thus, it is not entirely clear which of these two effects prevail when participants have to choose between two uncertain loot boxes. In contrast, when paired together with perceived behavioral control, the certainty effect is attenuated, such that users are more likely to prefer an uncertain loot box when they perceive to be more in control.

\section{Theoretical contributions}

This study contributes in three important ways to the emerging research on gamblification in general and on loot box menu designs for enhancing digital product offerings within digital business models in particular.

First, we contribute to IS research by providing insights on the nascent research on gamblification. From a broader perspective, we tease the unique features of gamblification and how gamblification elements differ from gamification elements. Whereas substantial research has investigated gamification and explicitly acknowledged the possibility of "uncertain" outcomes in game elements (e.g., Liu et al., 2017; Bartle, 1996), the more distinct and specific characteristics and effects of gamblification elements have received little attention so far. Our study not only answer calls for research that stress the importance of peculiarities of design elements (e.g., Hamari et al., 2014; Schöbel et al., 2020; Huotari \& Hamari, 2017) but also advances theory and research by providing insights for a more nuanced understanding of the impact of design elements by highlighting their contextualized usage through gamblification. As such, following the framework by Corley and Gioia (2011), we believe

\section{Probabilities of winning the reward}

0 : Choice between uncertain \& uncertain

1: Choice between uncertain \& certain

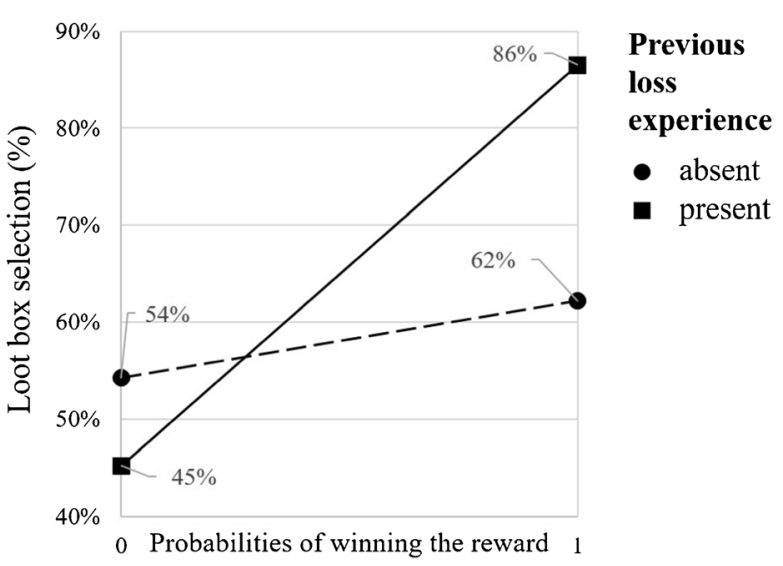




\section{Probabilities of winning the reward}

$\square$ uncertain \& uncertain

$\square$ uncertain \& certain

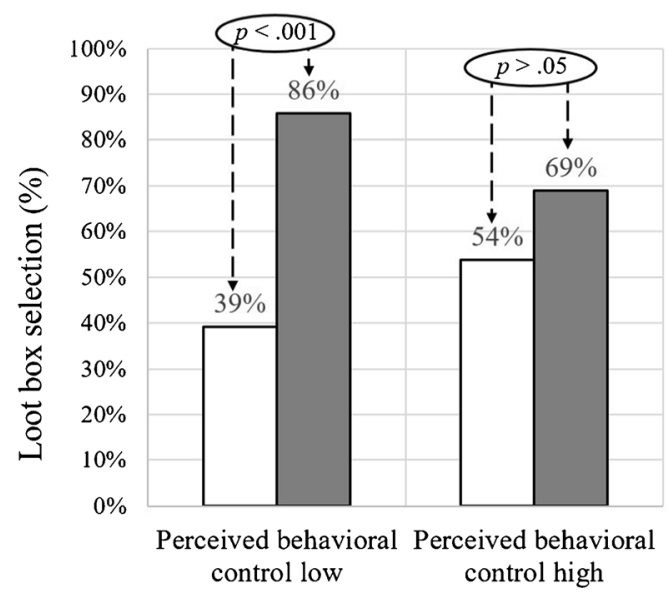

Fig. 7 Loot box selection when PBC is low vs. high

that gamblification provides (1) a new perspective on digital design elements for research and (2) important insights for practice by covering the prevalent phenomenon of gamblified digital product offerings in general and the multi-billion dollar market of loot box transactions in particular. In this study, we focused on the loot box menu design as one of the most prevalent forms of gamblification that currently shape many digital business models. Precisely, we investigate the effect of uncertain vs. certain rewards in loot box menu designs and how different combinations of probabilities of winning rewards drive purchase behavior (i.e., loot box selection) and thus revenue generation. Our results support the premise that probabilities of winning a reward in the form of "uncertain and uncertain" vs. "uncertain and certain" has an impact on users' purchase behaviors. Specifically, we demonstrate that information processing relevant for digital gaming monetization (i.e., evaluation of probabilities) can deviate from rational decision making as postulated by expected utility theory. Thereby, we assert that researchers should take alternative theoretical explanations (e.g., prospect theory) into account when they investigate and design loot box menus that utilize probabilistic uncertainty. Taken together, we enrich the nascent gamblification research by emphasizing the design of uncertainty-based mechanisms and how they may shape the success of digital business models through enhanced revenues.

Second, we shed light on the peculiar role of uncertainty in gamblified digital product offerings and highlight that due to the inherent uncertainty in gamblified settings the psychological effects governing user behavior are presumably different compared to non-gamblified settings. In particular, we investigate behavioral drivers specific to and salient in interactions in uncertain environments. In this regard, fear-of-losing which may be triggered by contextual factors such as loss previously experience is an important behavioral driver to consider.
Probabilities of winning the reward

0 : Choice between uncertain \& uncertain

1: Choice between uncertain \& certain



Additionally, individual factors such as ambitions-to-win which are represented by users' perceived behavior control is as well a crucial behavioral driver in gamblified settings. More specifically, our study provides knowledge on how to amplify and attenuate the certainty effect by considering two intriguing moderators that exhibit opposite effect patterns: Whereas previous loss experience amplifies the certainty effect, perceived behavior control attenuates the certainty effect. Consequently, we shed light on what factors in the environment need to be considered when designing and evaluating loot box menus, as the loot box menu does not exist in a vacuum but in tandem with variables in the digital surrounding.

Third and last, heeding Goes (2013) call for further research into the cognitive dimension of judgment in digital decision contexts, our study contributes nuanced insights into the burgeoning literature on cognitive biases in digital environments. More specifically, while previous studies have largely focused their investigations on attributes of a cognitive bias (e.g., continuity and linearity of anchoring effects) influencing consumer preferences in e-commerce (e.g., Adomavicius et al., 2013; Bodoff \& Vaknin, 2016), our findings from a randomized online experiment provide actionable design recommendations on how the certainty effect, distinctly and in combination with the availability heuristic and optimism bias, can be employed to shape conversion outcomes.

\section{Practical contributions}

This research has also important practical implications for digital platforms tasked with designing loot box menus and, more broadly, to help better understand the mechanism behind the microscopic economic behavior of individuals. Our study provides actionable design recommendations on how 
probabilities of winning a reward can be employed distinctly and in combination with previous loss experience to improve conversion behavior and thus revenues in digital business models. In this regard, if digital businesses choose the right menu design in similar settings, our results imply an average increase in revenue of up to $€ 0.82$ per decision $(+16.2 \%)$. This particularly applies to all digital business models incorporating uncertain elements, which are particularly prevalent in the 150-billion-dollar market of digital games (Wijman, 2020) and in particular in the 30-billion-dollar loot box market (Juniper Research, 2017). Moreover, our insights can also be transferred to uncertain offerings in e-commerce, such as the offering of surprise boxes (i.e., boxes containing uncertain selections of items fitting the customer preferences) (Xu, 2020). By providing a choice between two design elements, one containing a certain and the other an uncertain reward, providers can leverage the motivating uncertainty effect and simultaneously appeal to consumers who prefer to avoid uncertainty. Thus, they can optimize product differentiation in line with users' preference patterns. Nonetheless, when implementing those changes to better match users' preference patterns practitioners need to consider users' subjective perceptions and individual differences regarding their capabilities of mastering the gambling game. On the one hand, when users perceive a high level of behavioral control and thus believe their capabilities to be sufficient enough to master the gambling game increasing their ambitions-to-win, they are more likely to exhibit risk-seeking behavior (i.e., selecting a loot box with uncertain content) reducing the necessity for platform providers to offer different loot boxes with a certain or uncertain reward. On the other hand, when users perceive a low level of behavioral control their preferences are likely to be motivated by risk avoidance such that the product differentiation proposed above would lead to a better match of users' preference patterns. Likewise, practitioners need to consider contextual factor such as previous loss experience that may reduce the appeal of loot boxes with uncertain rewards. Taken together, practitioners should design their loot box menus with at least one certain reward offered to users with less ambitions to win and to users who previously experiences a loss. Conversely, users with a high ambition-to-win or users who didn't experience a loss beforehand are presumably attracted by loot boxes with uncertain rewards making it reasonable to offer these type of loot box menus to these user groups.

\section{Limitations and directions for future research}

The conducted study is an initial empirical investigation into the realm of gamblification and, thus, needs to be understood with respect to some noteworthy limitations that pave avenues for future research.
First, we investigated gamblification only in the form of gamblified digital business models through loot box menu designs. Although loot boxes represent one of the most common contemporary gamblification elements, several other forms (e.g., betting and card games) exist and require research. Indeed, gamblification comprises much more and promises many more venues for theory development above and beyond the gamblification of loot box menu design. Consequently, we encourage future research to shed more light on the potentials and consequences of gamblification. For instance, future studies can examine gamblification in a number of different nongambling contexts besides digital business models, such as enterprise systems and organizational contexts.

Second, utilizing a self-developed game and animated loot boxes during the experiment, we mimicked a realistic setting, making it easy for participants to be involved. Despite this high degree of realism of our experimental setting, our dependent variable was designed in such a way that it only captured a part of the conversion process. Participants had to choose between purchasing two different loot boxes. They were not able to decide whether they want to buy a loot box or not. Therefore, it would be interesting how the findings of our study would translate to a setting where explicit purchase decisions are undertaken. Specifically, how presenting just one loot box (e.g., the $90 \%$ loot box) without contrasting it with another or how presenting more than two loot boxes affects user purchase decisions.

Third, we implemented the probabilities of winning in a dichotomous (i.e., uncertain and uncertain vs. uncertain and certain) way and determined the specific values in both conditions (e.g., "50\%" and "60\%" vs. " $90 \%$ " and " $100 \%$ ") based on reference values in previous literature. However, it remains unclear how changing these reference values affect conversion behavior and whether linear or non-linear relationships can be expected. Future research is thus warranted to examine the linear or potentially non-linear relationships between the extent of changing the probabilities of winning and conversion behavior in digital business models. Moreover, future research should confirm and refine the results in a field study and in other cultural contexts to increase the robustness of our findings.

\section{Conclusion}

Because competition among digital platforms for regular and new customers has intensified, platform providers increasingly rethink how to design their digital business models to improve user onboarding and conversion outcomes. Gamblification promises not only to evoke excitement in users but also to increase revenues. In this research, we explain how loot box menus can be designed to increase revenue generation by shaping user decision-making. Specifically, we investigate through a contest- 
based online experiment how certain vs. uncertain rewards in loot box menus influence user purchase behavior. Our results demonstrate that platform providers can profit from offering certain (vs. uncertain) rewards in loot box menus. Moreover, this effect increases when participants previously experienced a loss and decreases when they perceive to have more control over the result. Thus, our findings provide insights on loot box menu designs to increase revenue generation. We hope that our findings not only provide an impetus for scholars to advance understanding of gamblification, but also offer actionable guidelines for providers to refine their knowledge about how they can effectively gamblify their digital business models.

Funding Open Access funding enabled and organized by Projekt DEAL.

Open Access This article is licensed under a Creative Commons Attribution 4.0 International License, which permits use, sharing, adaptation, distribution and reproduction in any medium or format, as long as you give appropriate credit to the original author(s) and the source, provide a link to the Creative Commons licence, and indicate if changes were made. The images or other third party material in this article are included in the article's Creative Commons licence, unless indicated otherwise in a credit line to the material. If material is not included in the article's Creative Commons licence and your intended use is not permitted by statutory regulation or exceeds the permitted use, you will need to obtain permission directly from the copyright holder. To view a copy of this licence, visit http://creativecommons.org/licenses/by/4.0/.

\section{References}

\section{Appendix}

Table 3 Measurement items

\begin{tabular}{|c|c|}
\hline Construct & Items \\
\hline $\begin{array}{l}\text { Perceived monetary value Hong } \\
\text { and Tam }(2006) \\
(\alpha=.87, \mathrm{AVE}=.75, \mathrm{CR}=.88)\end{array}$ & $\begin{array}{l}\text { I expect the option I have chosen to } \\
\text { have a reasonable price } \\
\text { My chosen option offers a good } \\
\text { value for its price } \\
\text { I believe that my chosen option } \\
\text { offers a good value for its current } \\
\text { price }\end{array}$ \\
\hline $\begin{array}{l}\text { Risk aversion Gray and Durcikova } \\
(2005) \\
(\alpha=.75, \mathrm{AVE}=.54, \mathrm{CR}=.57)\end{array}$ & $\begin{array}{l}\text { I am a cautious person who } \\
\text { generally avoids risk } \\
\text { I am very willing to take risks when } \\
\text { choosing a job or project to work } \\
\text { on } \\
\text { I usually play it safe, even if it } \\
\text { means occasionally losing out on } \\
\text { a good opportunity }\end{array}$ \\
\hline $\begin{array}{l}\text { Product involvement Fuller et al. } \\
\text { (2009) }\end{array}$ & I am interested in loot boxes \\
\hline $\begin{array}{l}\text { Perceived behavioral control } \\
\text { Venkatesh et al. }(2003)(\alpha=.82 \text {, } \\
\quad \mathrm{AVE}=.69, \mathrm{CR}=.82)\end{array}$ & $\begin{array}{l}\text { I have the resources necessary to } \\
\text { play the game } \\
\text { I have the knowledge necessary to } \\
\text { play the game }\end{array}$ \\
\hline
\end{tabular}

Note: Items were measured using a 7-point Likert-type scale ranging from strongly disagree (1) to strongly agree (7); $\alpha$ = Cronbach's alpha; $\mathrm{AVE}=$ Average variance extracted $C R=$ Composite reliability

Table 4 Frequency distribution of loot box spending scale

\begin{tabular}{llll}
\hline & Loot box spending & $\mathrm{N}$ & \\
\hline 1 & $0-10 €$ & 133 & $83.6 \%$ \\
2 & $11-50 €$ & 18 & $11.3 \%$ \\
3 & $51-150 €$ & 7 & $4.4 \%$ \\
4 & over $150 €$ & 1 & $0.7 \%$ \\
\hline
\end{tabular}

Adam M., Wessel M., \& Benlian, A. (2020) AI-based chatbots in customer service and their effects on user compliance. Electronic Markets, 1-19. https://doi.org/10.1007/s12525-020-00414-7.

Adomavicius, G., Bockstedt, J. C., Curley, S. P., \& Zhang, J. (2013). Do recommender systems manipulate consumer preferences? A study of anchoring effects. Information Systems Research, 24(4), 956975. https://doi.org/10.1287/isre.2013.0497.

Allais, M. (1953). Le comportement de l'homme rationnel devant le risque: Critique des postulats et axiomes de l'ecole americaine. Econometrica, 21(4), 503-546. https://doi.org/10.2307/1907921.

Baroudi, J. J., \& Orlikowski, W. J. (1989). The problem of statistical power in MIS research. MIS Quarterly, 13, 87-106. https://doi. org/10.2307/248704.

Bartle, R. (1996). Hearts, clubs, diamonds, spades: Players who suit MUDs. Journal of MUD Research, 1(1), 19-36.

Benlian, A. (2015). Web personalization cues and their differential effects on user assessments of website value. Journal of Management Information Systems, 32(1), 225-260. https://doi.org/10.1080/ 07421222.2015 .1029394$.

Benlian, A., Klumpe, J., \& Hinz, O. (2020). Mitigating the intrusive effects of smart home assistants by using anthropomorphic design features: A multimethod investigation. Information Systems Journal, 30(6), 1010-1042. https://doi.org/10.1111/isj.12243.

Bleichrodt, H., \& Schmidt, U. (2002). A context-dependent model of the gambling effect. Management Science, 48(6), 802-812. https://doi. org/10.1287/mnsc.48.6.802.190.

Bodoff, D., \& Vaknin, E. (2016). Priming effects and strategic influences in social tagging. Human-Computer Interaction, 31(2), 133171. https://doi.org/10.1080/07370024.2015.1080609.

Cohen, J. (1992). A power primer. Psychological Bulletin, 112(1), 155159. https://doi.org/10.1037//0033-2909.112.1.155.

Corley, K. G., \& Gioia, D. A. (2011). Building theory about theory building: What constitutes a theoretical contribution? Academy of Management Review, 36(1), 12-32. https://doi.org/10.5465/amr. 2009.0486

Croson, R., \& Sundali, J. (2005). The gambler's fallacy and the hot hand: Empirical data from casinos. Journal of Risk and Uncertainty, 30(3), 195-209. https://doi.org/10.1007/s11166-005-1153-2.

Daniels, D. P., \& Zlatev, J. J. (2019). Choice architects reveal a bias toward positivity and certainty. Organizational Behavior and Human Decision Processes, 151, 132-149. https://doi.org/10. 1016/j.obhdp.2018.12.004.

Dunning, D., Heath, C., \& Suls, J. M. (2004). Flawed self-assessment: Implications for health, education, and the workplace. Psychological Science in the Public Interest, 5(3), 69-106. https:// doi.org/10.1111/j.1529-1006.2004.00018.x. 
Fabbri, M., Nicola Barbieri, P., \& Bigoni, M. (2019). Ride your luck! A field experiment on lottery-based incentives for compliance. Management Science, 65(9), 4336-4348. https://doi.org/10.1287/ mnsc.2018.3163.

Faul, F., Erdfelder, E., Buchner, A., \& Lang, A.-G. (2009). Statistical power analyses using $\mathrm{G}^{*}$ power 3.1: Tests for correlation and regression analyses. Behavior Research Methods, 41(4), 11491160. https://doi.org/10.3758/BRM.41.4.1149.

FIFA Analytics (2020). List of packs. https://fifa-analytics.com/20/list-ofpacks. Accessed 16 Aug 2020.

FIFAUTEAM (2020). FIFA points prices. https://www.fifauteam.com/ fifa-points-prices-fifa-20/. Accessed 15 Aug 2020.

Fornell, C., \& Larcker, D. F. (1981). Evaluating structural equation models with unobservable variables and measurement error. Journal of Marketing Research, 18(1), 39-50. https://doi.org/10. $2307 / 3151312$.

Fortune, E. E., \& Goodie, A. S. (2012). Cognitive distortions as a component and treatment focus of pathological gambling: A review. Psychology of Addictive Behaviors, 26(2), 298-310. https://doi. org/10.1037/a0026422.

Fuller, J., Muhlbacher, H., Matzler, K., \& Jawecki, G. (2009). Consumer empowerment through internet-based co-creation. Journal of Management Information Systems, 26(3), 71-102. https://doi.org/ 10.2753/MIS0742-1222260303.

Gibson, B., \& Sanbonmatsu, D. M. (2004). Optimism, pessimism, and gambling: The downside of optimism. Personality and Social Psychology Bulletin, 30(2), 149-160. https://doi.org/10.1177/ 0146167203259929.

Goes, P. B. (2013). Editor's comments: Information systems research and behavioral economics. MIS Quarterly, 37(3), iii-viii.

Goldsmith, K., \& Amir, O. (2010). Can uncertainty improve promotions? Journal of Marketing Research, 47(6), 1070-1077. https://doi.org/ 10.1509/jmkr.47.6.1070.

Goodie, A. S., \& Fortune, E. E. (2013). Measuring cognitive distortions in pathological gambling: Review and meta-analyses. Psychology of Addictive Behaviors, 27(3), 730-743. https://doi.org/10.1037/ a0031892.

Google (2020). Google pay about. https://pay.google.com/intl/en_in/ about/. Accessed 13 Aug 2020.

Gray, P. H., \& Durcikova, A. (2005). The role of knowledge repositories in technical support environments: Speed versus learning in user performance. Journal of Management Information Systems, 22(3), 159-190. https://doi.org/10.2753/MIS0742-1222220306.

Griffiths, M. D. (2018). Is the buying of loot boxes in video games a form of gambling or gaming? Gaming Law Review, 22(1), 52-54. https:// doi.org/10.1089/glr2.2018.2216.

Guo, H., Hao, L., Mukhopadhyay, T., \& Sun, D. (2019). Selling virtual currency in digital games: Implications for gameplay and social welfare. Information Systems Research, 30(2), 430-446. https:// doi.org/10.1287/isre.2018.0812.

Guryan, J., \& Kearney, M. S. (2008). Gambling at lucky stores: Empirical evidence from state lottery sales. American Economic Review, 98(1), 458-473. https://doi.org/10.1257/aer.98.1.458.

Hamari, J., \& Keronen, L. (2016). Why do people buy virtual goods? A literature review. Paper presented at the 49th Hawaii international conference on system sciences (HICSS). https://doi.org/10.1109/ HICSS.2016.171.

Hamari, J., \& Keronen, L. (2017). Why do people buy virtual goods: A meta-analysis. Computers in Human Behavior, 71, 59-69. https:// doi.org/10.1016/j.chb.2017.01.042.

Hamari, J., \& Lehdonvirta, V. (2010). Game design as marketing: How game mechanics create demand for virtual goods. International Journal of Business Science and Applied Management, 5(1), 14-29.

Hamari, J., Koivisto, J., \& Sarsa, H. (2014). Does gamification work? A literature review of empirical studies on gamification. In: 47th
Hawaii international conference on system sciences (HICSS), pp. 3025-3034. https://doi.org/10.1109/HICSS.2014.377.

Harviainen, J. T., Ojasalo, J., \& Kumar, S. N. (2018). Customer preferences in mobile game pricing: A service design based case study. Electronic Markets, 28(2), 191-203. https://doi.org/10.1007/ s12525-018-0285-6.

Helweg-Larsen, M., \& Shepperd, J. A. (2001). Do moderators of the optimistic bias affect personal or target risk estimates? A review of the literature. Personality and Social Psychology Review, 5(1), 74 95. https://doi.org/10.1207/S15327957PSPR0501_5.

Hinz, O., Spann, M., \& Hann, I.-H. (2015). Research note - can't buy me love...or can I? Social capital attainment through conspicuous consumption in virtual environments. Information Systems Research, 26(4), 859-870. https://doi.org/10.1287/isre.2015.0596.

Ho, S. Y., Bodoff, D., \& Tam, K. Y. (2011). Timing of adaptive web personalization and its effects on online consumer behavior. Information Systems Research, 22(3), 660-679. https://doi.org/10. 1287/isre.1090.0262.

Hong, S.-J., \& Tam, K. Y. (2006). Understanding the adoption of multipurpose information appliances: The case of mobile data services. Information Systems Research, 17(2), 162-179. https://doi.org/10. 1287/isre. 1060.0088 .

Huotari, K., \& Hamari, J. (2017). A definition for gamification: Anchoring gamification in the service marketing literature. Electronic Markets, 27(1), 21-31. https://doi.org/10.1007/s12525015-0212-z.

Juniper Research (2017). In-game gambling the next cash cow for publishers [Whitepaper]. https://www.juniperresearch.com/whitepapers/in-game-gambling-the-next-cash-cow.

Kahneman, D. (2011). Thinking, fast and slow. Macmillan.

Kahneman, D., \& Tversky, A. (1979). Prospect theory: An analysis of decision under risk. Econometrica, 47(2), 263-291. https://doi.org/ $10.2307 / 1914185$.

King, D. L., \& Delfabbro, P. H. (2019). Video game monetization (eg, 'loot boxes'): A blueprint for practical social responsibility measures. International Journal of Mental Health and Addiction, 17(1), 166-179. https://doi.org/10.1007/s11469-018-0009-3.

Klein, C. T., \& Helweg-Larsen, M. (2002). Perceived control and the optimistic bias: A meta-analytic review. Psychology and Health, 17(4), 437-446. https://doi.org/10.1080/0887044022000004920.

Koch, O. F., \& Benlian, A. (2017). The effect of free sampling strategies on freemium conversion rates. Electronic Markets, 27(1), 6776. https://doi.org/10.1007/s12525-016-0236-z.

Koivisto, J., \& Hamari, J. (2019). The rise of motivational information systems: A review of gamification research. International Journal of Information Management, 45, 191-210. https://doi.org/10.1016/j. ijinfomgt.2018.10.013.

Lehdonvirta, V. (2009). Virtual item sales as a revenue model: Identifying attributes that drive purchase decisions. Electronic Commerce Research, 9(1), 97-113. https://doi.org/10.1007/ s10660-009-9028-2.

Liu, D., Santhanam, R., \& Webster, J. (2017). Toward meaningful engagement: A framework for design and research of gamified information systems. MIS Quarterly, 41(4), 1011-1034. https://doi.org/ 10.25300/MISQ/2017/41.4.01.

Liu, C.-W., Gao, G., \& Agarwal, R. (2019). Unraveling the "social" in social norms: The conditioning effect of user connectivity. Information Systems Research, 30(4), 1272-1295. https://doi.org/ 10.1287/isre.2019.0862.

Lowry, P. B., Moody, G. D., Galletta, D. F., \& Vance, A. (2013). The drivers in the use of online whistle-blowing reporting systems. Journal of Management Information Systems, 30(1), 153190. https://doi.org/10.2753/MIS0742-1222300105.

Ma, X., Kim, S. H., \& Kim, S. S. (2014). Online gambling behavior: The impacts of cumulative outcomes, recent outcomes, and prior use. 
Information Systems Research, 25(3), 511-527. https://doi.org/10. 1287/isre.2014.0517.

Macey, J., \& Hamari, J. (2019). eSports, skins and loot boxes: Participants, practices and problematic behaviour associated with emergent forms of gambling. New Media \& Society, 21(1), 20-41. https://doi.org/10.1177/1461444818786216.

MacKenzie, S. B., Podsakoff, P. M., \& Podsakoff, N. P. (2011). Construct measurement and validation procedures in MIS and behavioral research: Integrating new and existing techniques. MIS Quarterly, 35(2), 293-334. https://doi.org/10.2307/23044045.

Mazar, N., Shampanier, K., \& Ariely, D. (2017). When retailing and Las Vegas meet: Probabilistic free price promotions. Management Science, 63(1), 250-266. https://doi.org/10.1287/mnsc.2015.2328.

Overwatch Wiki (2019). Loot box. https://overwatch.fandom.com/wiki/ Loot_Box.

Penenberg, A. L. (2015). Play at work: How games inspire breakthrough thinking. Portfolio.

Riot Games (2019). Hextech crafting FAQ. https://supportleagueoflegends.riotgames.com/hc/en-us/articles/360036422453. Accessed 18 Dec 2019.

Rogers, P. (1998). The cognitive psychology of lottery gambling: A theoretical review. Journal of Gambling Studies, 14(2), 111134. https://doi.org/10.1023/A:1023042708217.

Rosenblat, A., \& Stark, L. (2016). Algorithmic labor and information asymmetries: A case study of Uber's drivers. International Journal of Communication, 10, 27. https://doi.org/10.2139/ssrn. 2686227.

Roethke, K., Klumpe, J., Adam, M., \& Benlian, A. (2020). Social influence tactics in e-commerce onboarding: The role of social proof and reciprocity in affecting user registrations. Decision Support Systems, 131, 113268. https://doi.org/10.1016/j.dss.2020.113268.

Schneider, D., Klumpe, J., Adam, M., \& Benlian, A. (2020). Nudging users into digital service solutions. Electronic Markets, 30(4), 863881. https://doi.org/10.1007/s12525-019-00373-8.

Schöbel, S., Janson, A., Jahn, K., Kordyaka, B., Turetken, O., Djafarova, N., Saqr, M., Wu, D., Söllner, M., Adam, M., Heiberg Gad, P., Wesserloh, H., \& Leimeister, J. M. (2020). A research agenda for the why, what, and how of gamification designs results on an ECIS 2019 panel. Communications of the Association for Information Systems, 47. https://doi.org/10.17705/1CAIS.04630.

Shen, L., Fishbach, A., \& Hsee, C. K. (2014). The motivating-uncertainty effect: Uncertainty increases resource investment in the process of reward pursuit. Journal of Consumer Research, 41(5), 13011315. https://doi.org/10.1086/679418.

Starbucks (2020). Starland. https://www.starbucksrewardsstarland. com/\#/. Accessed 15 Aug 2020.

Takatalo, J., Häkkinen, J., Kaistinen, J., \& Nyman, G. (2010) Presence, involvement, and flow in digital games. In: Bernhaupt $\mathrm{R}$. (Eds.) Evaluating user experience in games. Concepts and Methods (pp. 23-46). Springer. https://doi.org/10.1007/978-184882-963-3 3.

Thaler, R. H., \& Johnson, E. J. (1990). Gambling with the house money and trying to break even: The effects of prior outcomes on risky choice. Management Science, 36(6), 643-660. https://doi.org/10. $1287 / \mathrm{mnsc} .36 .6 .643$

Thiebes, S., Lins, S., \& Basten, D. (2014). Gamifying information systems-A synthesis of gamification mechanics and dynamics. 22nd European Conference on Information Systems (ECIS).

Tversky, A., \& Kahneman, D. (1973). Availability: A heuristic for judging frequency and probability. Cognitive Psychology, 5(2), 207 232. https://doi.org/10.1016/0010-0285(73)90033-9.

Tversky, A., \& Kahneman, D. (1986). Rational choice and the framing of decisions. The Journal of Business, 59(4), 251-278.

Uber (2020). Driver profiles. https://eng.uber.com/driver-profiles/. Accessed 17 Aug 2020.

Veit, D., Clemons, E., Benlian, A., Buxmann, P., Hess, T., Kundisch, D., Leimeister, J. M., Loos, P., \& Spann, M. (2014). Business models. Business \& Information Systems Engineering, 6(1), 45-53. https:// doi.org/10.1007/s12599-013-0308-y.

Venkatesh, V., Morris, M. G., Davis, G. B., \& Davis, F. D. (2003). User acceptance of information technology: Toward a unified view. MIS Quarterly, 27(3), 425-478. https://doi.org/10.2307/30036540.

Voigt, S., \& Hinz, O. (2016). Making digital freemium business models a success: Predicting customers' lifetime value via initial purchase information. Business \& Information Systems Engineering, 58(2), 107-118. https://doi.org/10.1007/s12599-015-0395-z.

Von Neumann, J., \& Morgenstern, O. (2007). Theory of games and economic behavior (commemorative edition). Princeton, $\mathrm{NJ}$ : Princeton University Press.

Wagner, T. M., Benlian, A., \& Hess, T. (2014). Converting freemium customers from free to premium - the role of the perceived premium fit in the case of music as a service. Electronic Markets, 24(4), 259 268. https://doi.org/10.1007/s12525-014-0168-4.

Wärneryd, K.-E. (1996). Risk attitudes and risky behavior. Journal of Economic Psychology, 17(6), 749-770. https://doi.org/10.1016/ S0167-4870(96)00034-7.

Weinmann, M., Schneider, C., \& vom Brocke, J. (2016). Digital nudging. Business \& Information Systems Engineering, 58(6), 433436. https://doi.org/10.1007/s12599-016-0453-1.

Weinstein, N. D., \& Lachendro, E. (1982). Egocentrism as a source of unrealistic optimism. Personality and Social Psychology Bulletin, 8(2), 195-200. https://doi.org/10.1177/0146167282082002.

Wijman, T. (2020). The world's 2.7 billion gamers will spend $\$ 159.3$ billion on games in 2020; the market will surpass $\$ 200$ billion by 2023. Newzoo. https://newzoo.com/insights/articles/newzoogames-market-numbers-revenues-and-audience-2020-2023/. Accessed 10 Aug 2020.

$\mathrm{Xu}, \mathrm{X}$. (2020). Examining the role of emotion in online consumer reviews of various attributes in the surprise box shopping model. Decision Support Systems, 136, 113344. https://doi.org/10.1016/j.dss.2020. 113344.

Publisher's note Springer Nature remains neutral with regard to jurisdictional claims in published maps and institutional affiliations. 